\title{
Effect of radiotherapy on oral mucosa assessed by quantitative exfoliative cytology
}

\author{
G R OGDEN,* J G COWPE,* M W GREEN
}

From the Departments of *Dental Surgery and Mathematics and Computer Science, University of Dundee, Scotland

SUMMARY The effect of radiotherapy on normal buccal mucosa was investigated using the quantitative techniques of cytomorphology (measurement of nuclear and cytoplasmic area) and DNA cytophotometry. These techniques were applied to smears obtained before, during, and after irradiation. Nuclear area and cytoplasmic area increased and DNA values were abnormal in most cases as a result of radiotherapy, returning to within normal limits one month after treatment. This contrasts strongly with the changes seen in smears from previously irradiated uterine cervices, where changes in cytomorphology may persist for several years.

Exfoliative cytology of the uterine cervix continues to be a routine and widely practised method for the screening of cervical cancer. ${ }^{1-3}$ Its application to the screening for oral cancer has fallen from favour, due mainly to the subjective nature of its interpretation. ${ }^{-6}$ Recently, quantitative techniques, such as computerised analysis of digitised cell images ${ }^{78}$ and DNA cytophotometry ${ }^{9}$ have been applied to cervical smears. Unfortunately, few have applied these techniques to the detection of oral cancer. ${ }^{10} 11$

Although oral cancer accounts for only $2 \%$ of all malignant tumours, ${ }^{12}$ its five year survival of $25 \%$ remains disappointingly low. ${ }^{13-15}$ Ninety per cent of all oral cancers that recur do so within the first two years of treatment. ${ }^{12}$ For quantitative exfoliative cytology to be of value in the detection of malignant change (either primary or recurrent), the effect of various external or systemic factors on normal mucosa must first be assessed..$^{16}$

To detect recurrence following radiotherapy the effect of radiation on normal mucosa must be known, particularly as the irradiation of normal tissue may result in altered DNA states and malignant change itself. ${ }^{1718}$ The aim of this study, therefore, was to assess the effect of radiotherapy on the DNA distribution and cytomorphology of normal oral mucosa and the duration of any change observed. Such knowledge could help differentiate malignancy from radiation damage where suspicious areas of previously irradiated oral mucosa exist.

\section{Material and methods}

All patients received megavoltage therapy $(4 \mathrm{MeV})$ using a source to skin distance of $100 \mathrm{~cm}$. Most patients received parallel opposing fields and requiredoc wedges. Every patient required a beam directed shell, : which meant that the normal buccal mucosa was irradiated during every fractionated dose. The volume irradiated, however, varied among patients, as did the number of fractions and total dose recieved. A full blood count was taken to exclude anaemia for each patient.

Smears were obtained from normal buccal mucosa which was in the field of exposure, for the irradiation of malignant tumours. These smears were taken before, two weeks into, and at one month review following completion of radiotherapy. A wooden tongue spatula was scraped firmly across the mucosa, and the scrapings transferred to glass slides. The smears for DNA estimation were fixed in methanol:formalin:acetic acid (85:10:5) and then underwent Feulgen hydrolysis. ${ }^{19}$ The smears for cytomorphological assessment (measurement of nuclear area and cytoplasmic area) were fixed in equal parts of $95 \%$ ethanol and diethylether and then stained with the Papanicolaou stain.

DNA measurements were carried out using a Vickers M85 scanning and integrating microdensitometer. For each smear the Feulgen DNA content of 50 randomly selected nuclei was measured. DNA distribution histograms were compiled for each specimen. 
For cytomorphological assessment, the nuclear and cell boundaries of 50 randomly selected cells were traced using a Leitz drawing tube attached to the microscope, at $\times 1000$ magnification. The nuclear and cytoplasmic areas were then calculated using a Reichhert digitiser interfaced to a Pet 2000 computer and then analysed on the University of Dundee's PRIME computer, using the Minitab statistical package.

\section{Results}

Thirty seven patients were screened; 27 were men (mean age 61.4 years) and 10 were women (mean age 62.6 years). The malignant lesions affected the tongue, floor of mouth, palate, tonsilar region, buccal mucosa, mandible, parotid and submandibular glands.

The results for DNA distribution of 25 of the 37 patients are listed in table 1 . In the remaining 12 patients smears were obtained at two of the three "stages". These smears were incomplete due to a number of factors beyond our control-for example, patients declined to consent, failed to return, died or were reviewed outside the Dundee district. The diploid (D) state was characterised by a one peak DNA distribution. The abnormal state (DS) described a smear in which most cells were diploid, but in which one or two abnormal nuclei existed. Polyploidy (P)

Table 1 The dose received and its effect on the DNA profiles of normal buccal mucosa are displayed together with the timing of smear taken after treatment

\begin{tabular}{llllll}
\hline $\begin{array}{l}\text { Case } \\
\text { No }\end{array}$ & Before & Halfway & After & $\begin{array}{l}\text { Months } \\
\text { after } \\
\text { treatment }\end{array}$ & $\begin{array}{l}\text { Radiotherapy } \\
\text { Regimens } \\
\text { (fractions } \\
\text { TMax cGys }\end{array}$ \\
\hline 1 & D & P & D & 5 & $\times 20 / 4500$ \\
2 & D & D & D & 1 & $\times 25 / 5500$ \\
3 & D & P & D & $1 \cdot 5$ & $\times 23 / 5500$ \\
4 & D & D & D & $0 \cdot 5$ & $\times 20 / 5300$ \\
5 & D & D & D & $0 \cdot 5$ & $\times 10 / 3000$ \\
6 & D & D & D & 17 & $\times 18 / 4000$ \\
7 & D & D & D & 1 & $\times 10 / 1200$ \\
8 & D & D & D & $0 \cdot 25$ & $\times 20 / 5500$ \\
9 & D & D & P & $0 \cdot 25$ & $\times 20 / 6000$ \\
10 & D & D & D & 3 & $\times 20 / 5280$ \\
11 & D & P & D & $0 \cdot 5$ & $\times 25 / 6000$ \\
12 & D & P & D & 1 & $\times 20 / 4500$ \\
13 & D & P & D & 1 & $\times 25 / 5250$ \\
14 & D & P & D & $1 \cdot 75$ & $\times 20 / 4750$ \\
15 & D & D & D & 1 & $\times 24 / 5500$ \\
16 & D & P & D & $1 \cdot 5$ & $\times 20 / 5593$ \\
17 & D & P & D & 3 & $\times 20 / 5145$ \\
18 & D & P & D & $1 \cdot 5$ & $\times 20 / 5216$ \\
19 & D & D & D & 2 & $\times 10 / 3250$ \\
20 & D & P & D & $1 \cdot 25$ & $\times 20 / 5500$ \\
21 & D & P & D & $0 \cdot 5$ & $\times 15 / 3656$ \\
22 & D & P & D & $0 \cdot 5$ & $\times 15 / 3574$ \\
23 & D & Ds & D & $0 \cdot 5$ & $\times 20 / 5200$ \\
24 & D & P & D & 1 & $\times 20 / 5900$ \\
25 & D & D & D & $0 \cdot 25$ & $\times 20 / 4106$ \\
\hline
\end{tabular}

Tmax-total dose received. referred to a DNA distribution representing various multiples of the diploid state.

The treatment was interrupted after 10 fractions (split course), to begin again two weeks later in cases 5 , $7,9,11,23,24$. Smears taken half way through treatment were taken immediately the 10 fractions were completed. The radiotherapy regimens ranged from 1200 cGys over 10 fractions, to $6000 \mathrm{cGys}$ over 20 fractions.

The buccal mucosa before irradiation was always diploid. In 25 of the 33 cases smeared half way through treatment an abnormal DNA state was observed. At initial review after radiotherapy smears were obtained from 31 cases, four of which dislayed abnormal DNA profiles.

The values for nuclear area and cytoplasmic area are illustrated in the form of boxplots (figure). The means and standard deviations for each stage of treatment smeared are given in table 2. Using a two sample $t$ test, a highly significant rise in both nuclear area $(p=0.002)$ and cytoplasmic area $(p=0.001)$ resulted from exposure to irradiation (before treatment compared with half way through treatment). This highly significant rise in both nuclear area and cytoplasmic area values (significant at the $1 \%$ level) was followed by an almost equal reduction in both values

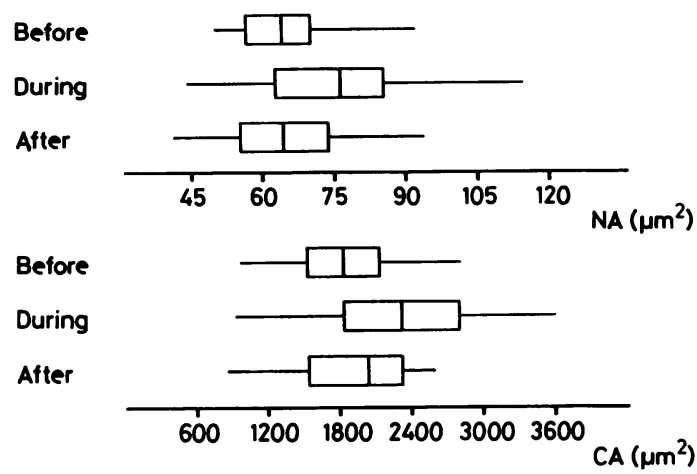

Figure Boxplots to show effects of radiotherapy on nuclear area $(N A)$ and cytoplasmic area $(C A)$ values. The vertical line within the box depicts the median value (50th percentile); the box depicts the first and third quartiles.

Table 2 The mean values for nuclear area $(N A)$ and cytoplasmic area (CA) for smears collected before, during and after completion of radiotherapy

\begin{tabular}{lll}
\hline $\begin{array}{l}\text { Stage of } \\
\text { treatment }\end{array}$ & $\begin{array}{l}\text { Nuclear area }\left(\mu \mathrm{m}^{2}\right) \\
\text { Mean }(S D)\end{array}$ & $\begin{array}{l}\text { Cytoplasmic area }\left(\mu \mathrm{m}^{2}\right) \\
\text { Mean }(S D)\end{array}$ \\
\hline Before & $64.9(10.97)$ & $1876(560)$ \\
Halfway through & $75.4(16.66)$ & $2333(669)$ \\
After & $65.6(13.44)$ & $1932(478)$ \\
\hline
\end{tabular}


at review. A two sample $t$ test comparing smears taken after treatment with those taken before showed no significant difference (nuclear area, $p=0.87$, cytoplasmic area, $p=0.76$ ).

\section{Discussion}

All smears taken before irradiation were diploid, confirming Cowpe et al $\mathrm{s}^{16}$ previous findings in the normal mucosa of healthy non-anaemic subjects. In most cases radiotherapy induced a change within the DNA state. At review, however, most cases had returned to the diploid DNA state.

Abnormalities within DNA profiles are usually associated with malignancy. ${ }^{111}$ The finding of such changes within normal mucosa, however, should not be so surprising, given that ionising irradiation is known to be mutagenic and capable of causing neoplasia. ${ }^{17} 18$ What is perhaps more surprising is that we do not see tumours developing more often within previously irradiated normal mucosa. In our study, however, these radiation damaged cells did not retain their proliferative ability; an abnormal DNA profile was rarely found four weeks after treatment. This may have been due to DNA repair, further lethal damage of cells already changed, or possibly because the cells found during radiotherapy were genetically mute.

In some cases the changed DNA state persisted into the phase after treatment. Of the four cases with abnormal DNA profiles after treatment, three were smeared two weeks after treatment. Gillespie observed that the cells of the oral mucosa take five days to migrate to the surface, ${ }^{20}$ hence these changes were possibly due to direct radiation damage. The abnormal DNA profile in the fourth case was due to recurrence." Unfortunately, it was not possible to smear the other three cases at weekly intervals to determine the point at which they reverted to the diploid state, but later smears were all diploid. Whether the prolongation in abnormal DNA state was indicative of a poor tissue response and subsequent poor prognosis is unclear as two of these patients died shortly after completing treatment. Another patient died within three months of completing treatment and yet had displayed a diploid DNA profile.

With regard to cytomorphology, both nuclear area and cytoplasmic area increased as a result of radiotherapy, although at review no significant difference was found between values obtained before and after treatment. This was despite there being a lack of standardisation in the total incident dose. Variations in quantity and quality of saliva, nutritional state, and superimposed infection may have occurred during treatment, which may have influenced cytomorphological values.
Umiker et al reported two peaks in nuclear area and cytoplasmic area enlargement in normal buccal mucosa cells during treatment (one between 12 and 19 days, the other between 25 and 38 days). ${ }^{21}$ Smears taken half way through treatment would have coincided with the development of Umiker's first peak. The second peak could not be confirmed because our cases were not treated for that length of time.

The possibility remains that there may be late, radiation induced effects. ${ }^{22} 23$ Cytoplasmic vacuolation, multinucleation, and cell enlargement have been observed in normal oral mucosa for several years after radiotherapy ${ }^{24}{ }^{25}$ although others have not found cell enlargement. ${ }^{26}$ No changes in nuclear area, cytoplasmic area, and DNA profile seem to be present in our cases under long term review. This contrasts with cervical smears where radiation induced changes, which may include an increase in nuclear area and cytoplasmic area, can persist for several years. ${ }^{27} 28$

In conclusion, this study indicates that any changed DNA state arising in normal buccal mucosa as a consequence of irradiation returns to a diploid state within four to six weeks of radiotherapy. Hence these high doses of irradiation, while being capable of inducing dysplasia (as indicated by the changed DNA state) seem to have no lasting effect on DNA distribution. This was also true for increases in nuclear area and cytoplasmic area, which returned to normato values after completion of treatment. Recently it has been advised that cervical smears should continue to be taken for life because radiation carcinogenesis may occur. ${ }^{23}$ Similar doses are used for oral tumours, which emphasises the need to evaluate the effect of radiotherapy on normal oral mucosa, both in the short and long term.

We thank Drs S Das and J Dewar (department of radiotherapy and oncology, Ninewells Hospital) for access to their patients, Mrs Morag Thompson for her excellent technical assistance, and Mrs C Toner for typing the manuscript.

\section{References}

1 Papanicolaou GN. Atlas of exfoliative cytology. Cambridge, Massachusetts: Harvard Press, 1954.

2 Boon ME, Tabbers-Boumeester ML. Gynaecological cytology. A textbook and atlas. London: Macmillan Press Ltd, 1980.

3 Dawang $Y$, Jufang $Y$, Shoufu X, Yixian L. Mass cytologic screening for cervical carcinoma in China. A review of 7,735,057 reported cases. Acta Cytol 1985;29:341-4.

4 Dabelsteen E, Roed-Petersen B, Smith CJ, Pindborg JJ. The limitations of exfoliative cytology for the detection of epithelial atypia in oral leukoplakias. Br J Cancer 1971;25:21-4.

5 Folson TC, White CP, Bromer L, Canby HF, Garrington GE. Oral exfoliative study. Review of the literature and report of a 3 year study. Oral Surg 1972;33:61-74.

6 Reddy CR, Kameswari VR, Prahlad D, Ramuly C, Reddy PG. 
Correlative study of exfoliative cytology and histopathology of oral carcinomas. J Oral Surg 1975;33:435-8.

7 Bibbo M, Bartels PH, Sychra JJ, Wied GL. Chromatin appearance in intermediate cells from patients with uterine cancer. Acta Cytol 1980;25:23-8.

8 Gavin PM, Gray M, Sutton J,Claydon AD, Banks RI, Bird CC. Morphometric differences between cytologically benign and malignant serous effusions. Acta Cytol 1988;32:175-82.

9 Bocking D, Hilgarth M, Auffermann W, Hack-Werdier C, Fischer-Becker D, Von Kalkreuth G. DNA-Cytometric diagnosis of prospective malignancy in borderline lesions of the uterine cervix. Acta Cytol 1986;30:608-15.

10 Cowpe JG, Longmore RB, Green MW. Quantitative exfoliative cytology of abnormal oral mucosal smears. J Roy Soc Med 1988;81:509-13.

11 Ogden GR, Cowpe JG. Quantitative cytophotometric analysis as aid to the detection of recurrent oral cancer. British Journal of Oral and Maxillofacial Surgery 1989;27:224-8.

12 Henk JM, Langdon JD. Natural history, response to treatment and prognosis in Malignant tumours of the oral cavity, London: Edward Arnold, 1985:53-69.

13 Glucksman A, Walter L, Cherry CP. The role of serial biopsies in the treatment of oral cancer. Clin Radiol 1967;18:310-12.

14 Langdon JD, Harvey PW, Rapidis AD, Patel MF, Johnson NW, Hopps R. Oral cancer: the behaviour and response to treatment of 194 cases. Journal of Maxillofacial Surgery 1977;5:221-37.

15 Berger W, Goldstein J, Strawberry C. Clinical experiences in managing head and neck squamous carcinoma. Ear, Nose and Throat Journal 1984;63:591-6.

16 Cowpe JG, Longmore RB, Green MW. Quantitative exfoliative cytology of normal oral squames: an age, site and sex related survey. J Roy Soc Med 1985;78:995-1004.

17 Modan B, Mart M, Baidatz D. Radiation induced head and neck cancers. Lancet 1974;1:277-9.

18 Walker KE, Leibel SA, Wara WM. Squamous cell carcinoma of the head and neck after radiation therapy for Hodgkin's disease. Cancer 1985;56:1052-5.

19 Cowpe JG, Longmore RB. Nuclear area and Feulgen DNA content of normal buccal mucosal smears. J Oral Pathol 1981;10:81-6.

20 Gillespie GM. Renewal of buccal epithelium. Oral Surg 1969;27: 83-9.

21 Umiker WO, Weatherbee L, Rapp R, Boblit DE. Cytologic effects of irradiation in oral smears: A study of the changes in benign squamous cells. University of Michigan Medical Bulletin 1957;23:264-75.

22 Sirota DK, Eden AR, Biller HF. Multiple head and neck neoplasia following radiation for benign disease during childhood. J Surg Oncol 1988;38:101-3.

23 Storm HH. Second primary cancer after treatment for cervical cancer: late effects after radiotherapy. Cancer 1988;61:679-88.

24 Silverman S, Sheline GE, Gillooly CJ. Radiation therapy and oral carcinoma. Radiation response and exfoliative cytology. Cancer 1967;20:1297-300.

25 Peters H. Cytologic smears from the mouth, cellular changes in diseases and after radiation. Am J Clin Pathol 1958;29:219-25.

26 Mouriquand J, Dargent M, Papillon J. Radiation cell changes in cells from the oral cavity. Acta Cytol 1959;3:451-4.

27 Graham RM. The effect of radiation on vaginal cells in cervical carcinomas. Surg Gynecol Obstet 1947;84:153-73.

28 Graham RM, Graham JB. Cytological prognosis in cancer of the uterine cervix treated radiologically. Cancer 1955;8::59-70.

Requests for reprints to: Dr G R Ogden, Department of Dental Surgery, Dental School, Park Place, Dundee, Scotland. 